\title{
Stability of molar relationship after non-extraction Class II malocclusion treatment
}

\author{
Darwin Vaz de Lima¹, Karina Maria Salvatore de Freitas², Marcos Roberto de Freitas ${ }^{3}$, \\ Guilherme Janson 3 , José Fernando Castanha Henriques ${ }^{3}$, Arnaldo Pinzan ${ }^{4}$
}

Objective: This study aimed to evaluate the stability of molar relationship after non-extraction treatment of Class II malocclusion. Methods: The sample comprised 39 subjects (16 females, 23 males) with initial Class II malocclusion treated with no extractions, using fixed appliances. Mean age at the beginning of treatment was 12.94 years, at the end of treatment was 15.14 years and at post-retention stage was 21.18 years. Mean treatment time was 2.19 years and mean time of post-treatment evaluation was 6.12 years. To verify the influence of the severity of initial Class II molar relationship in stability of molar relationship, the sample was divided into two groups, one presenting a $1 / 2$-cusp or $3 / 4$-cusp Class II molar relationship, and the other with full-cusp Class II molar relationship. In dental casts from initial, final and postretention stages, molar, first and second premolars and canine relationships were measured. Data obtained were analyzed by dependent ANOVA, Tukey and Pearson's correlation tests, as well as independent $t$ test between the two groups divided by severity of initial molar relationship. Results: There was a non-statistically significant $0.12 \mathrm{~mm}$ relapse of molar relationship. The initial severity of Class II molar relationship was not correlated to relapse in the post-retention period. When compared, the two groups showed no difference in relapse of molar relationship. Conclusion: It was concluded that correction of Class II molar relationship is stable and initial severity does not influence relapse of molar relationship.

Keywords: Corrective orthodontics. Angle Class II malocclusion. Treatment outcomes.

Objetivo: esse estudo objetivou avaliar a estabilidade da relação molar na má oclusão de Classe II tratada ortodonticamente sem extrações, visando quantificar a recidiva e correlacioná-la a alguns fatores. Métodos: a amostra constituiu-se de 39 indivíduos (16 mulheres e 23 homens) com má oclusão de Classe II tratada sem extrações, com aparelhos fixos. A idade inicial média foi de 12,94 anos; na fase final, foi de 15,14 anos; na pós-contenção, 21,18 anos. A média do tempo de tratamento foi de 2,19 anos e do tempo de avaliação pós-tratamento, de 6,12 anos. Para verificar a influência da severidade da relação molar de Classe II inicial na estabilidade da relação molar, a amostra foi dividida em dois grupos, um apresentando relação molar de 1/2 Classe II ou 3/4 de Classe II, e outro apresentando relação molar de Classe II completa. Nos modelos de estudo das três fases estudadas, foram medidas a relação molar, as relações de primeiros e segundos pré-molares e de caninos. Os dados foram analisados pelos testes ANOVA dependente, de Tukey, correlação de Pearson e teste $t$ independente entre dois grupos, divididos pela severidade da relação molar inicial. Resultados: houve recidiva não significativa de $0,12 \mathrm{~mm}$ na relação molar. A severidade inicial da relação molar de Classe II não se correlacionou com a recidiva no período pós-contenção. Quando a amostra dividiu-se em dois grupos, nenhuma diferença foi encontrada na recidiva da relação molar. Conclusão: a correção da relação molar de Classe II é estável e a severidade inicial não exerce influência sobre a recidiva da relação molar.

Palavras-chave: Ortodontia corretiva. Má oclusão de Angle Classe II. Resultado de tratamento.

${ }^{1}$ Professor, Specialization Course in Orthodontics, UNORP

${ }^{2}$ Post-Doctor in Orthodontics, University of Toronto. Head Professor of the Master Course in Orthodontics, UNINGÁ.

${ }^{3}$ Professor of Orthodontics, FOB-USP.

${ }^{4}$ Associate Professor of Orthodontics, FOB-USP.

" The author reports no commercial, proprietary or financial interest in the products or companies described in this article.
How to cite this article: Lima DV, Freitas KMS, Freitas MR, Janson G, Henriques JFC, Pinzan A. Stability of molar relationship after non-extraction Class II malocclusion treatment. Dental Press J Orthod. 2013 Mar-Apr;18(2):42-54.

Submitted: March 20, 2009 - Revised and accepted: August 16, 2009

Contact address: Karina Maria Salvatore de Freitas

Rua Jamil Gebara, 1-25, apto. 111 - Bauru / SP, Brazil - CEP: 17.017-150

E-mail: kmsf@uol.com.br 


\section{INTRODUCTION}

Class II malocclusion does not self-correct in growing patients. ${ }^{8,17}$ The Class II skeletal pattern is established early and remains until puberty if no orthodontic intervention is performed. ${ }^{8}$

To this date, several authors have discussed the relationship of the initial malocclusion characteristics with the effectiveness of orthodontic treatment ${ }^{22,31,40}$ and the stability of the corrections obtained. .,33,43 $^{2}$

Normally, orthodontic treatment takes a long time and uses complex techniques, usually achieving good results; however, these results may be lost in varying degrees after the removal of appliances and retainers. ${ }^{38}$ Orthodontic relapse includes crowding or spacing of teeth, and loss of overbite, overjet correction, and loss of Class II molar relationship correction.

Orthodontic changes of the position of the first permanent molars have a great tendency to relapse. ${ }^{24}$ Some authors affirm that Class I molar relationship is more stable compared to others and, over time, the mandibular molar tends to distalize in patients with Class II malocclusion. ${ }^{17}$ For Uhde, Sadowsky and BeGole, ${ }^{39}$ changes that occur in molar relationship are always towards Class II relation. The changes are of small magnitude and independent of the type of initial malocclusion and the type of treatment. Other authors suggest that, in the long-term, there is minimal relapse in molar relationship and that changes in incisor position and intercuspation of the posterior teeth are statistically significant, although not considered clinically significant. ${ }^{12,39}$

The stability of Class II malocclusion has been widely studied, however, few studies that have actually evaluated relapse and stability of the correction of Class II molar relationship in models. The studies are mostly directed to a particular type of appliance or treatment protocol.

In this context, the objective of this study was to evaluate the stability of molar relationship in cases with initial Class II malocclusion, treated orthodontically without extractions, correlating with factors such as the severity of initial Class II molar relationship, treatment, retention and post-retention times. Moreover, the objective was to compare the post retention stability of molar relationship between two groups divided according to the severity of the initial Class II molar relationship.

\section{MATERIAL AND METHODS}

For the present retrospective study, the sample was obtained from the records of the Department of Orthodontics, Bauru Dental School, University of São Paulo.

The inclusion criteria comprised the following characteristics:

» Angle Class II malocclusion, treated without extractions.

"Presence of erupted permanent teeth up to first molars, at the beginning of orthodontic treatment.

"Absence of tooth agenesis and supernumerary teeth.

"No anomalies in size and / or shape of the teeth.

"Absence of rotations of the maxillary and mandibular molars in the initial models, which could influence variable measurement.

"Orthodontic treatment with fixed appliances, which may include the use of headgear and / or Class II intermaxillary elastics.

" Complete orthodontic records, including study models of pre and post treatment and post retention records.

All patients in the sample were Caucasian, of both genders. The study models of the pretreatment $\left(\mathrm{T}_{1}\right.$ - initial $)$, posttreatment $\left(\mathrm{T}_{2}-\right.$ final $)$ and post-retention phases $\left(\mathrm{T}_{3}\right.$ - post-retention at least 2 years after the end of treatment) were used.

The sample was composed of a total of 39 patients, 16 females and 23 males. The mean age at pretreatment was $12.94 \pm 1.21$ years, the mean age at the end of treatment was $15.14 \pm 1.38$ years, and the mean age at post-retention was $21.18 \pm 2.65$ years. The mean treatment time was $2.19 \pm 0.83$ years. The mean posttreatment time evaluation, (between the final and post-retention stages) was $6.30 \pm 2.60$ years. At the end of active orthodontic treatment all patients used a removable Hawley plate retainer in the maxillary arch and a bonded fixed retainer from canine to canine in the mandibular arch. The retainers were used, on average, $1.62 \pm 0.49$ years.

To evaluate the influence of the severity of the initial Class II molar relationship in the stability of molar relationship, the sample was divided into two groups: Group 1, 16 patients presenting half-cusp or 3/4-cusp initial Class II molar relationship. The mean age at 
pretreatment was $13.27 \pm 1.11$ years, the mean age at the end of treatment was $15.10 \pm 1.35$ years and the mean age at post-retention was $20.18 \pm 2.03$ years. The mean treatment time was $1.83 \pm 0.49$ years, the mean retention time was $1.58 \pm 0.55$ years and the mean time between posttreatment and post-retention phases was $5.29 \pm 1.57$ years. Group 2 consisted of 23 patients with a complete initial Class II molar relationship. The mean age at pretreatment was $12.71 \pm 1.25$ years, the mean age at the end of treatment was $15.17 \pm 1.42$ years and the mean age at post-retention was $21.87 \pm 2.84$ years. The mean treatment time was $2.45 \pm 0.94$ years, the mean retention time was $1.69 \pm 0.46$ years and the mean time between posttreatment and post-retention phases was $6.70 \pm$ of 2.46 years.

The orthodontic records of the selected sample were used to obtain some relevant data for this work. Clinical records were examined for therapeutic procedures at pre and posttreatment, and the posttreatment followups. The date of removal of retainers was also observed. These data, together with the patient's date of birth, allowed accurate determination of the total time of treatment, control, posttreatment, post-retention, retention time and age of the patients in the studied phases.

The study models concerning initial, final and post-retention stages of each patient were evaluated. Study models were photographed with a D-80 camera, with $105 \mathrm{~mm}$ close-up lens (AF-S VR Micro Nikkor $105 \mathrm{~mm} \mathrm{f/2.8G} \mathrm{IF-ED,} \mathrm{Nikon} \mathrm{Corporation,} \mathrm{Japan)}$ and circular flash (Nikon Corporation, Japan) with 300 dpi (dots per inch). From each study model, two lateral photographs were obtained, one on the right side and one on the left, with the buccal surfaces of posterior teeth parallel to each other. All photographs were obtained with the same distance between the object and the lens $(31.4 \mathrm{~cm})$, to avoid magnification.

The digital images were inserted into a computer and analyzed with Dolphin Imaging software version 10 (Dolphin Imaging and Management Solutions, Chatsworth, CA, USA). This program magnifies each image by means of their size in dpi. For each variable, two points are marked and the distance between them was calculated by the software. The accuracy of measurements was $0.01 \mathrm{~mm}$. For the statistical analysis, the mean right and left sides of each measurement was obtained. The calculated variables are presented in the following topics.

\section{Molar relationship}

The molar relationship was measured from the tip of the mesiobuccal cusp of the maxillary first molar to the mesiobuccal groove of the mandibular first molar (Fig 1). The average of right and left sides was used.

\section{Second premolar relationship}

The relationship of the second premolars was measured from the tip of the buccal cusp of the maxillary second premolar to the distal anatomical contact point between the mandibular second premolar and the mesial of the mandibular first molar (Fig 2). The average of right and left sides was used.

\section{First premolar relationship}

The relationship of first premolars was measured from the tip of the buccal cusp of the maxillary first premolar to the distal anatomical contact point of the mandibular first premolar and mesial of the mandibular second premolar (Fig 3). The average of right and left sides was used.

\section{Canine relationship}

The canine relationship was measured from the cusp tip of the maxillary canine to the anatomical contact point between the distal mandibular canine and the mesial of the mandibular first premolar (Fig 4). The average of right and left sides was used.

\section{Statistical analysis}

Method error

The intra-examiner error was evaluated by taking new measurements of the initial, final and post-retention study models of 15 patients randomly selected, performing a total of 45 pairs of models. The first and second measurements were performed with a time interval of one month. The formula proposed by Dahlberg ${ }^{11}\left(\mathrm{Se}^{2}=\Sigma \mathrm{d}^{2} / 2 \mathrm{n}\right)$ was applied to estimate the magnitude of casual errors, while systematic errors were analyzed by applying the paired $t$ test, according to Houston. ${ }^{19}$

\section{Statistical treatment}

Descriptive statistics were performed for the variables at the initial $\left(\mathrm{T}_{1}\right)$, final $\left(\mathrm{T}_{2}\right)$ and post-retention $\left(\mathrm{T}_{3}\right)$ phases, and for the differences between initial and final, (characterizing treatment correction), and 


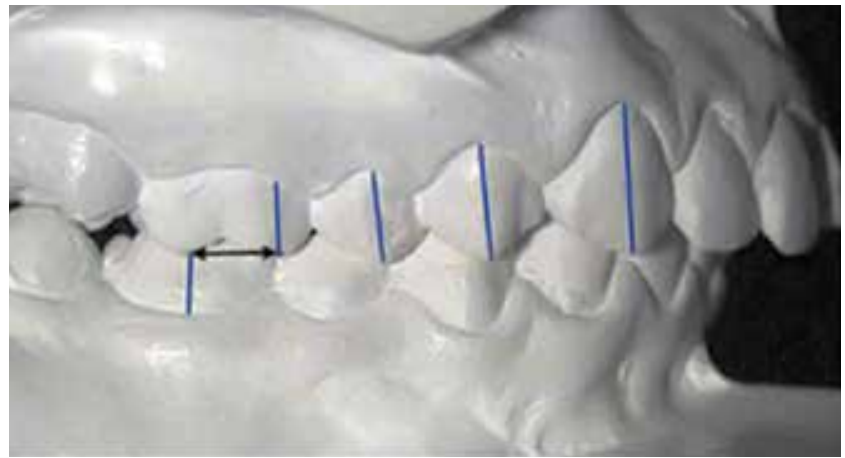

Figure 1 - Molar relationship measurement.

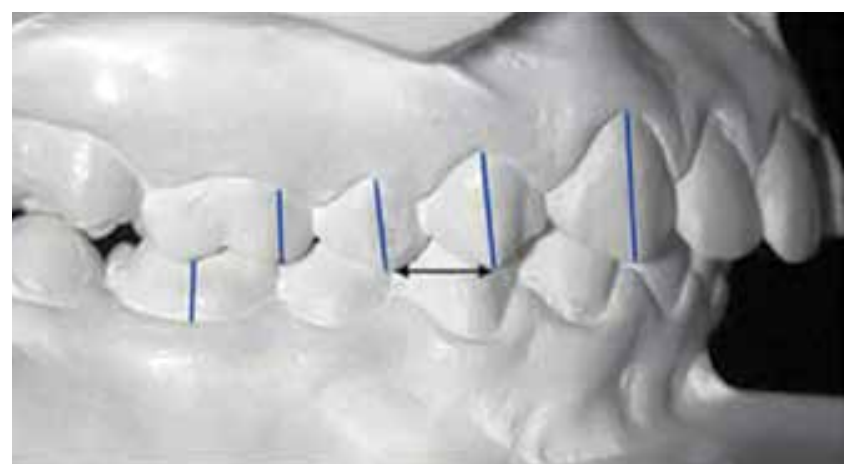

Figure 3 - First pre-molars relationship measurement.

between the final and post-retention stages, (characterizing the change during post-retention). There was also descriptive statistics of the ages at initial, final and post-retention stages and the duration of treatment, retention and post-retention evaluation.

To evaluate variable changes between phases, the dependent ANOVA for repeated measures (repeated measures ANOVA) was used and in the presence of a significant result, Tukey's test was applied subsequently.

The Pearson correlation coefficient was calculated to verify the presence of correlation between molar relationship relapse with: severity of initial Class II relationship, treatment time, retention time and time of post-retention evaluation.

To better evaluate the influence of the initial Class II molar relationship severity on the stability of molar relationship, the sample was divided into two groups: Group 1 with $1 / 2$-cusp or 3/4-cusp initial molar Class II relationship, and Group 2, with ini-

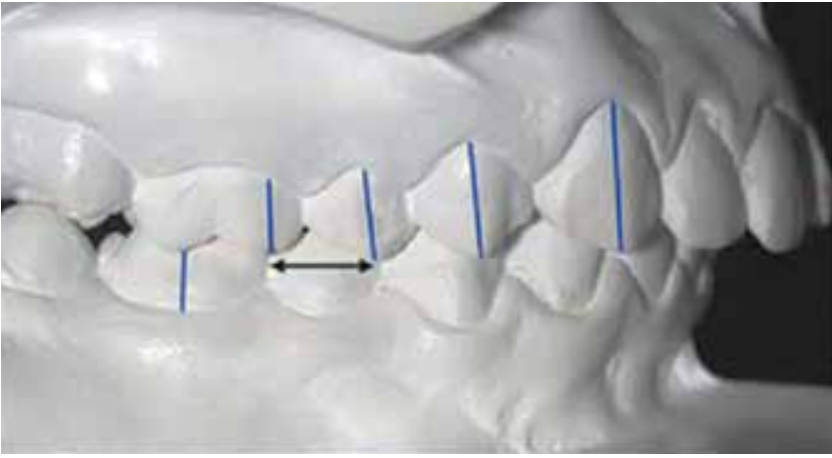

Figure 2 - Second pre-molars relationship measurement.

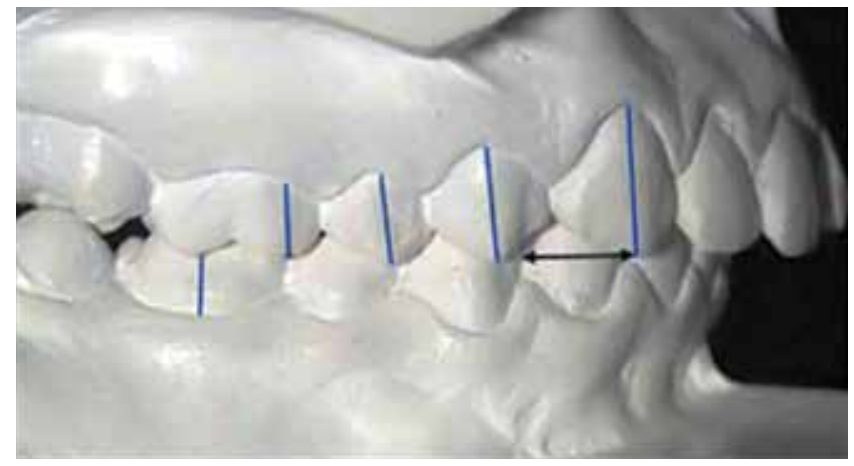

Figure 4 - Canines relationship measurement.

tial complete Class II molar relationship. Therefore, the independent $t$ test was applied for all variables between these two groups.

All tests were performed with the STATISTICA software (Statistica for Windows, Release 6.0, Copyright StatSoft, Inc. 2001), adopting a significance level of $5 \%$.

\section{RESULTS}

Table 1 presents the results of the evaluation of systematic and casual errors, by evaluating the paired $t$ test and Dahlberg' formula, ${ }^{11}$ applied to all studied variables.

The descriptive statistics results (mean, standard deviation, minimum, maximum and number) of the variables molar relationship (MR), second premolars relationship (2PMR), first premolars relationship (1PMR) and canine relationship (CR) in every evaluated stage $\left(\mathrm{T}_{1}, \mathrm{~T}_{2}\right.$ and $\left.\mathrm{T}_{3}\right)$ and periods $\left(\mathrm{T}_{2}-\mathrm{T}_{1}\right.$ and $T_{3}-T_{2}$ ) are shown in Tables 2 to 5 . 
Table 6 shows the results of the analysis of variance (ANOVA) and Tukey's test for the variables molar relationship, relationship of first and second premolars and canines, at the initial, final and postretention stages.

Table 7 presents the results of the Pearson correlation test to evaluate the correlation of the severity of Class II relationship with the post-retention relapse.

Table 8 shows the test results of the Pearson correlation test to determine the correlation of relapse and treatment time, retention time and time of postretention evaluation.

Table 9 presents the results of the independent $t$ test between groups 1 ( $1 / 2$-cusp or $3 / 4$-cusp Class II) and 2 (complete Class II).

\section{DISCUSSION}

\section{Methods}

From the medical records of each patient general data such as date of birth, gender, type of appliance and mechanics used, date of beginning and end of treatment, duration of the use of the retainers, date of post-retention evaluation were collected. With these data, treatment, retention and posttreatment evalua- tion times, age at the beginning and end of treatment, and at post-retention stage was assessed.

The choice of the methodology to be used should be based on the objective of the study. Since the purpose of this study was to evaluate the stability and relapse of molar relationship in the post-retention stage, the best method for evaluating molar relationship are study models. Although this method does not allow the clinical and radiographic analysis, the study models alone provide information related to diagnosis and orthodontic treatment. ${ }^{6,15}$ Furthermore, it has been shown that there is a poor association among the occlusal characteristics and the morphology obtained in the lateral cephalograms and better prediction of orthodontic results can be obtained by occlusal indexes than by cephalometrics. ${ }^{1}$ The fact that occlusal characteristics do not always reflect craniofacial morphology was evidenced by Pancherz, Zieber and Hoyer, ${ }^{35}$ who observed similar cephalometric characteristics when comparing Class II, division 1 and 2, contradicting the widespread idea that the severe overbite of Class II division 2 malocclusion is related to a more horizontal skeletal pattern of this malocclusion. ${ }^{21}$ Although this
Table 1 - Results of t test and Dahlberg formula, applied to the variables molar relationship, second premolar relationship, first premolar relationship and canine relationship, for estimation of systematic and casual errors, respectively $(n=45)$.

\begin{tabular}{ccccccc}
\hline & \multicolumn{2}{c}{ 1st. } & \multicolumn{2}{c}{ 2nd. } & \\
Variables & Measurement & \multicolumn{2}{c}{ Measurement } & Dahlberg & p \\
& Mean & SD & Mean & SD & & \\
\hline MR & 2.03 & 1.80 & 2.08 & 1.88 & 0.21 & 0.183 \\
\hline 2PMR & 3.47 & 2.05 & 3.54 & 2.05 & 0.26 & 0.056 \\
\hline 1PMR & 3.35 & 2.15 & 3.40 & 2.16 & 0.16 & 0.099 \\
\hline CR & 4.40 & 2.29 & 4.43 & 2.21 & 0.27 & 0.530 \\
\hline
\end{tabular}

Table 2 - Results of the descriptive statistical analysis for the variable molar relationship (MR), in all stages and periods evaluated.

\begin{tabular}{cccccc}
\hline Variables & Mean & SD & Minimum & Maximum & n \\
\hline$M R T_{1}$ & 4.65 & 1.52 & 1.85 & 8.40 & 39 \\
$\mathrm{MRT}_{2}$ & 0.50 & 0.70 & 0.00 & 3.05 & 39 \\
$\mathrm{MR}_{3}$ & 0.62 & 0.74 & 0.00 & 2.80 & 39 \\
$\mathrm{MRT}_{2}-T_{1}$ & -4.14 & 1.47 & -7.15 & -0.85 & 39 \\
$\mathrm{MR} \mathrm{T}_{3}-\mathrm{T}_{2}$ & 0.12 & 0.78 & -2.10 & 2.50 & 39 \\
\hline
\end{tabular}

Table 3 - Results of the descriptive statistical analysis for the variable second premolar relationship (2PMR), in all stages and periods evaluated.

\begin{tabular}{cccccc}
\hline Variables & Mean & SD & Minimum & Maximum & n \\
\hline $2 \mathrm{PMR} \mathrm{T}_{1}$ & 5.89 & 1.73 & 2.50 & 9.15 & 39 \\
\hline $2 \mathrm{PMR} \mathrm{T}_{2}$ & 1.39 & 0.83 & 0.20 & 3.55 & 39 \\
\hline $2 \mathrm{PMR} \mathrm{T}_{3}$ & 1.60 & 0.94 & 0.00 & 4.25 & 39 \\
\hline $2 \mathrm{PMR} \mathrm{T}_{2}-\mathrm{T}_{1}$ & -4.50 & 1.65 & -8.20 & -0.95 & 39 \\
\hline $2 \mathrm{PMR} \mathrm{T}_{3}-\mathrm{T}_{2}$ & 0.21 & 0.90 & -1.60 & 2.85 & 39 \\
\hline
\end{tabular}

Table 4 - Results of the descriptive statistical analysis for the variable first premolars relationship (1PMR), in all stages and periods evaluated.

\begin{tabular}{cccccc}
\hline Variables & Mean & SD & Minimum & Maximum & n \\
\hline 1PMR $T_{1}$ & 5.88 & 1.64 & 2.30 & 9.75 & 39 \\
\hline PMR $T_{2}$ & 1.03 & 0.78 & 0.00 & 2.80 & 39 \\
\hline $1 P M R T_{3}$ & 1.33 & 0.82 & 0.00 & 3.35 & 39 \\
\hline PMR $_{2}-T_{1}$ & -4.85 & 1.71 & -9.40 & -0.30 & 39 \\
\hline PMR $_{3}-T_{2}$ & 0.30 & 0.73 & -1.15 & 2.05 & 39 \\
\hline
\end{tabular}


Table 5 - Results of the descriptive statistical analysis for the variable canine relationship (CR), in all stages and periods evaluated.

\begin{tabular}{cccccc}
\hline Variables & Mean & SD & Minimum & Maximum & n \\
\hline $\mathrm{CR}_{1}$ & 7.22 & 1.64 & 2.75 & 10.45 & 39 \\
$\mathrm{CRT}_{2}$ & 2.32 & 0.94 & 0.55 & 4.70 & 39 \\
$\mathrm{CRT}_{3}$ & 2.28 & 1.04 & 0.20 & 5.55 & 39 \\
$\mathrm{CR} \mathrm{T}_{2}-\mathrm{T}_{1}$ & -4.89 & 1.65 & -8.85 & 0.60 & 39 \\
$\mathrm{CR} \mathrm{T}_{3}-\mathrm{T}_{2}$ & -0.04 & 0.89 & -1.80 & 2.50 & 39 \\
\hline
\end{tabular}

Table 7 - Results of the Pearson's correlation test to verify the correlation of the severity of the Class II relationship with the post-retention relapse.

\begin{tabular}{ccc}
\hline Correlations & $\mathbf{r}$ & $\mathbf{p}$ \\
\hline$M R T_{1} \times M R T_{3}$ & 0.107 & 0.515 \\
$M R T_{1} \times M R T_{3}-T_{2}$ & -0.173 & 0.292 \\
\hline $2 P M R T_{1} \times 2 P M R T_{3}$ & 0.143 & 0.382 \\
\hline $2 P M R T_{1} \times 2 P M R T_{3}-T_{2}$ & -0.159 & 0.331 \\
\hline $1 P M R T_{1} \times 1 P M R T_{3}$ & -0.012 & 0.938 \\
$1 P M R T_{1} \times 1 P M R T_{3}-T_{2}$ & -0.172 & 0.293 \\
\hline$C R T_{1} \times C R T_{3}$ & -0.049 & 0.763 \\
\hline$C R T_{1} \times C R T_{3}-T_{2}$ & -0.354 & $0.026 *$ \\
\hline
\end{tabular}

* Statistically significant difference for $p<0.05$
Table 6 - Results of the analysis of variance (ANOVA) and Tukey tests for the variables molar relationship, first and second premolars relationship and canine relationship $(n=39)$, between the initial, final and post-retention stages same letters mean no statistically significant difference).

\begin{tabular}{|c|c|c|c|c|}
\hline \multirow{2}{*}{ Variables } & Initial $\left(T_{1}\right)$ & Final $\left(T_{2}\right)$ & Post-retention $\left(\mathrm{T}_{3}\right)$ & \multirow{2}{*}{$\mathbf{p}$} \\
\hline & Mean \pm SD & Mean \pm SD & Mean \pm SD & \\
\hline MR & $4.65 \pm 1.52^{a}$ & $0.50 \pm 0.70^{b}$ & $0.62 \pm 0.74 b$ & $0.000 *$ \\
\hline 2PMR & $5.89 \pm 1.73$ & $1.39 \pm 0.83^{b}$ & $1.60 \pm 0.94^{b}$ & $0.000 *$ \\
\hline 1PMR & $5.88 \pm 1.64^{a}$ & $1.03 \pm 0.78^{b}$ & $1.33 \pm 0.82^{b}$ & $0.000 *$ \\
\hline$C R$ & $7.22 \pm 1.64^{a}$ & $2.32 \pm 0.94^{b}$ & $2.28 \pm 1.04^{b}$ & $0.000^{*}$ \\
\hline
\end{tabular}

* Statistically significant difference for $p<0.05$

Table 8 - Results of the Pearson's correlation test to verify the correlation of the relapse with treatment time, retention time and time of post-retention evaluation.

\begin{tabular}{ccc}
\hline Correlations & $\boldsymbol{r}$ & $\boldsymbol{p}$ \\
$M R \mathrm{~T}_{3}-\mathrm{T}_{2} \times$ TREATT & -0.205 & 0.210 \\
$M R T_{3}-T_{2} \times$ RETENT & -0.006 & 0.968 \\
$M R T_{3}-T_{2} \times$ POSTR & -0.373 & $0.019^{*}$ \\
\hline
\end{tabular}

* Statistically significant difference for $p<0.05$

Table 9 - Results of independent t test, between the groups divided in $1 / 2$-cusp or $3 / 4$-cusp Class II and complete Class II.

\begin{tabular}{|c|c|c|c|c|c|}
\hline \multirow{2}{*}{ Variables } & \multicolumn{2}{|c|}{ Group 1 - $1 / 2$-cusp or $3 / 4$-cusp Class II $(n=16)$} & \multicolumn{2}{|c|}{ Group 2 - Complete Class II (n=23) } & \multirow{2}{*}{$\mathbf{p}$} \\
\hline & Mean & SD & Mean & SD & \\
\hline $\mathrm{ID} \mathrm{T}_{1}$ & 13.27 & 1.11 & 12.71 & 1.25 & 0.164 \\
\hline $\mathrm{ID} \mathrm{T}_{2}$ & 15.10 & 1.35 & 15.17 & 1.42 & 0.895 \\
\hline $\mathrm{ID}_{3}$ & 20.18 & 2.03 & 21.87 & 2.84 & $0.048^{*}$ \\
\hline TREATT & 1.83 & 0.49 & 2.45 & 0.94 & $0.021^{*}$ \\
\hline RETENT & 1.58 & 0.55 & 1.65 & 0.46 & 0.685 \\
\hline POSTR & 5.29 & 1.57 & 6.70 & 2.46 & 0.051 \\
\hline$M R T_{1}$ & 3.53 & 1.03 & 5.43 & 1.31 & $0.000 *$ \\
\hline$M R T_{2}$ & 0.25 & 0.39 & 0.67 & 0.82 & 0.064 \\
\hline $\mathrm{MRT}_{3}$ & 0.48 & 0.78 & 0.72 & 0.71 & 0.339 \\
\hline$M R T_{2}-T_{1}$ & -3.28 & 1.17 & -4.75 & 1.36 & $0.001^{*}$ \\
\hline$M R T_{3}-T_{2}$ & 0.23 & 0.75 & 0.04 & 0.81 & 0.460 \\
\hline $2 \mathrm{PMR}_{1}$ & 4.52 & 0.90 & 6.84 & 1.52 & $0.000 *$ \\
\hline $2 \mathrm{PMR}_{2}$ & 0.91 & 0.62 & 1.72 & 0.81 & $0.001^{*}$ \\
\hline $2 \mathrm{PMR} \mathrm{T}_{3}$ & 1.33 & 0.95 & 1.79 & 0.92 & 0.141 \\
\hline $2 P M R T_{2}-T_{1}$ & -3.61 & 1.17 & -5.11 & 1.67 & $0.003^{*}$ \\
\hline $2 \mathrm{PMR} \mathrm{T}_{3}-\mathrm{T}_{2}$ & 0.42 & 0.76 & 0.06 & 0.98 & 0.230 \\
\hline $1 P M R T_{1}$ & 4.50 & 1.08 & 6.85 & 1.23 & $0.000^{*}$ \\
\hline $1 P M R T_{2}$ & 0.64 & 0.61 & 1.31 & 0.77 & $0.006^{*}$ \\
\hline $1 P M R T_{3}$ & 1.17 & 0.79 & 1.45 & 0.83 & 0.303 \\
\hline $1 P M R T_{2}-T_{1}$ & -3.86 & 1.40 & -5.53 & 1.59 & $0.001^{*}$ \\
\hline $1 P M R T_{3}-T_{2}$ & 0.53 & 0.63 & 0.13 & 0.75 & 0.096 \\
\hline $\mathrm{CR} \mathrm{T}_{1}$ & 6.00 & 1.73 & 8.07 & 0.89 & 0.000 * \\
\hline $\mathrm{CRT}_{2}$ & 1.96 & 0.83 & 2.58 & 0.95 & $0.043^{*}$ \\
\hline $\mathrm{CRT}_{3}$ & 2.23 & 0.84 & 2.31 & 1.18 & 0.804 \\
\hline$C R T_{2}-T_{1}$ & -4.04 & 1.77 & -5.49 & 1.29 & $0.005^{*}$ \\
\hline $\mathrm{CR} \mathrm{T}_{3}-\mathrm{T}_{2}$ & 0.26 & 0.88 & -0.26 & 0.85 & 0.067 \\
\hline
\end{tabular}

* Statistically significant difference for $p<0.05$. 
study did not use occlusal indexes, molar relationship measurement, a characteristic that can be well observed in study models, was used. ${ }^{6,9}$

Andrews ${ }^{4}$ defined the six keys to normal occlusion based exclusively on the information contained in 120 study models, and these six keys are valuable parameters to obtain an ideal static occlusion. Similarly, the occlusal evaluation is an important research tool regarding the results of orthodontic treatments. $2,7,43$ Therefore, this study performed the measurement of molar relationship on study models, a method that is simple and objective, and has previously been used in several studies. ${ }^{10,12,23,39}$

All measurements were made from photographs of the study models of the three phases for each patient. The study models were photographed with a D-80 camera, with a $105 \mathrm{~mm}$ close-up lens and circular flash (Nikon Corporation, Japan) with 300 dpi. The use of this lens prevents any distortion of the image. From each model, two lateral photographs were obtained, one of the right side and one of the left, with the buccal surfaces of the posterior teeth parallel to each other. The digital images were inserted into a computer and analyzed with Dolphin Imaging software version 10 (Dolphin Imaging and Management Solutions, Chatsworth, CA, USA). This program magnifies each image by means of the size in dpi, to be informed by the examiner. For each variable, two points are marked and the distance between them is thus calculated by the software. The accuracy of measurements was $0.01 \mathrm{~mm}$. For the statistical analysis, the average of the right and left sides of each of the measures was obtained.

The main advantage of this measurement method is that the images, once inserted in the Dolphin software, can be magnified on the computer screen, or even displayed with a multimedia projector, and the points marked with the aid of a mouse connected to the computer. This possibility of image magnification greatly facilitates the visualization of the point to be marked, minimizing the possible methodological errors, as shown in Table 1.

According to Houston, ${ }^{19}$ for an accurate analysis, the object of study should be reevaluated a minimum of 25 times. Thus, to evaluate the intra-examiner error, new measurements of the studied variables (molar relationship, relationship of second premolars, re- lationship of first premolars and canine relationship, Figures 1, 2, 3 and 4, respectively) were performed on study models of 15 patients randomly selected from the total sample, a total of 45 pairs of models, measured one month after the first measurement. The results of the two measurements were then subjected to the formula proposed by Dahlberg, ${ }^{11}$ to obtain the casual errors. To obtain the systematic errors, the paired $t$ test was applied.

The results demonstrated the absence of systematic errors. Casual errors were minimum and hence acceptable (Table 1). The greatest casual error occurred for the canine relationship (CR), with value of $0.27 \mathrm{~mm}$. The absence of significant systematic errors and the minimum value of the casual errors observed in this study may result from both the standardization and accuracy of the measurements, and also by the simplicity and objectivity of the measurement used, making this method very reliable and reproducible.

\section{Sample}

Since the main objective of this study was to evaluate the stability of molar relationship in the longterm, the selection of the sample was performed aiming to eliminate the largest possible number of factors that could influence the results. Therefore, to evaluate the stability of molar relationship, and also the relationships of first and second premolars and canines, it was necessary to standardize the initial characteristics and the several factors related to the orthodontic treatment. Therefore, the initial malocclusion was calibrated, regarding the type and minimum severity, the treatment protocol used, and the type of appliance.

Therefore, the basic criteria for sample selection was initially Angle Class II malocclusion, with molar relationship of at least half-cusp Class II. ${ }^{42}$ Cases could not present rotation of the maxillary and mandibular molars in the initial models, which could influence the measurement of the variables. In addition, all patients should have been treated with fixed orthodontic appliances ${ }^{14,37}$ in both maxillary and mandibular arches, without extractions. ${ }^{14,20,37}$ All patients used headgear in the maxillary arch and Class II elastics during orthodontic treatment.

Cases treated previously with functional, fixed and removable appliances, and with intraoral distalizers 
were excluded, which may influence the interpretation of the results of this study. It is known that the relapse of the skeletal changes of functional orthopedic appliances occurs after removal of the appliances, and this could influence the results. ${ }^{32,34}$ In addition, distalizers also perform a quick distalization of the maxillary molars and generally cause a distal tipping of the crown of these teeth, relapse may be increased in these cases, due to these factors. ${ }^{27,30}$

The presence of permanent teeth erupted up to the first molars and the absence of supernumerary teeth and agenesis constituted criteria of sample selection, since the absence of permanent teeth, the presence of supernumerary and some anomalies related to the shape of the teeth can interfere with the normal development of the occlusion, producing malocclusions that require correction with a different orthodontic mechanics, increasing the complexity and difficulty of the orthodontic treatment, and stability. ${ }^{6,25}$

The sample consisted of a total of 41 patients, selected from the records of the Discipline of Orthodontics, treated by Graduate students (from the Department of Pediatric Dentistry, Orthodontics and Public Health, Bauru Dental School). Only those cases that had complete orthodontic records were selected, with all the forms properly completed, presenting the study models from initial, final and at least two years posttreatment stages.

The time of posttreatment evaluation, in the postretention stage, is reasonable to observe the stability, one of the purposes of this study, because, according to Al Yami, Kuijpers-Jagtman and van't Hof, ${ }^{3}$ about half of the total relapse occurs in the first two years after the end of treatment, with good stability for most of the characteristics in the period of more than five years posttreatment.

The sample selection did not involve the factor quality of finishing, which did not serve as a criterion for exclusion or inclusion. However, assessing the Class II cases treated without extractions in FOB-USP, Barros ${ }^{6}$ found that even those cases where there is need for greater patient cooperation, ${ }^{20,41}$ were finished, in general, in an acceptable manner. Furthermore, it has been previously demonstrated that the quality of finishing is not related to the long-term results of orthodontic treatments, and an excellent finishing does not guarantee stability. ${ }^{13,29,33}$

\section{RESULTS}

\section{Molar relationship}

The measurement of the initial Class II molar relationship showed a mean value of $4.65 \mathrm{~mm}$, and was reduced to $0.50 \mathrm{~mm}$ after treatment. For the postretention evaluation, in the long-term, $0.62 \mathrm{~mm}$ was found (Table 2). This demonstrates a correction with treatment of $4.14 \mathrm{~mm}$ and a minimum relapse of only $0.12 \mathrm{~mm}$ (Table 2). As shown in Table 6, after performing the ANOVA and Tukey tests, a statistically significant correction with treatment and stability in the post-retention period could be noted, since there was no statistically significant difference in the molar relationship between the final and post-retention stages. In other words, the molar relationship showed to be stable in the post-retention phase.

The results of this study are in agreement with previous findings in the literature. ${ }^{10,12,23,39}$

Canut and Arias, ${ }^{10}$ evaluating Class II division 2 cases, found a mean of post-retention relapse of molar relationship of $0.6 \mathrm{~mm}$, and all patients had a good molar occlusion in the post-retention phase. The authors considered the molar relationship stable at the end of the post-retention period.

Kim and Little ${ }^{23}$ found even an improvement in molar relationship in the post-retention period evaluating Class II division 2 cases. At the end of treatment, the cases had a mean value of $1.3 \mathrm{~mm}$ for the molar relationship and, in post-retention stage, this value reduced to $1.2 \mathrm{~mm}$, suggesting an improvement in the molar relationship of $0.1 \mathrm{~mm}$.

Uhde, Sadowsky and BeGole, ${ }^{39}$ evaluating Class I and Class II cases in the post-retention stage, reported that the mean change in molar relationship is always in relation to the Class II, however, these changes are not relevant, (about $0.50 \mathrm{~mm}$ ). However, besides including Class I and Class II cases, which directly influences the results, the authors also included cases treated with and without extractions.

However, Fidler et $\mathrm{al}^{12}$ found a significant relapse of molar relationship between the final and post-retention stages. However, although statistically significant, this relapse had low values of $0.34 \mathrm{~mm}$ for the molar relationship on the right side and $0.33 \mathrm{~mm}$ on the left side. Perhaps this difference with the present study was due to the fact that the authors selected cases with Class II malocclusion treated successfully 
at the end of treatment, and in the present study, the final treatment outcome of the Class II was not considered for the sample selection.

The literature shows stability of the molar relationship, especially in Class II, division 2 cases. Regarding the Class II division 1 malocclusion, this study showed slightly better results than those found in the literature. ${ }^{12}$

\section{Second premolar relationship}

The initial measurement of the second premolars relationship presented a mean value of $5.89 \mathrm{~mm}$, being reduced to $1.39 \mathrm{~mm}$ after treatment. For the post-retention evaluation, in the long-term, $1.60 \mathrm{~mm}$ was found (Table 3). This demonstrates a correction of $4.50 \mathrm{~mm}$, and a relapse of $0.21 \mathrm{~mm}$ (Table 3). As shown in Table 6, after performing the ANOVA and Tukey tests, a statistically significant correction with treatment and stability in the post-retention period could be noted, since there was no statistically significant difference of the second premolars relationship between the final and post-retention stages.

The study of Kim and Little ${ }^{23}$ showed the same trend, however, in the final stage, the value of the premolars relationship was slightly higher than normal, and this value remained higher in the posttreatment stage. The initial value of the Class II premolars relationship was $4.6 \mathrm{~mm}$, being corrected to $2.2 \mathrm{~mm}$ at the end of treatment and relapsed to $2.5 \mathrm{~mm}$ in the post-retention stage.

\section{First premolar relationship}

The initial measurement of the first premolars relationship presented a mean value of $5.88 \mathrm{~mm}$, being reduced to $1.03 \mathrm{~mm}$ after treatment. For the postretention evaluation, in the long-term, $1.33 \mathrm{~mm}$ was found (Table 4). This demonstrates a correction of $4.85 \mathrm{~mm}$, and a relapse of $0.30 \mathrm{~mm}$ (Table 4). As shown in Table 6, after performing the ANOVA and Tukey tests, a statistically significant correction with treatment and stability in the post-retention period could be noted, since there was no statistically significant difference in the first premolars relationship between the final and post-retention stages.

\section{Canine relationship}

The initial measurement of the canine relationship presented a mean value of $7.22 \mathrm{~mm}$, being re- duced to $2.32 \mathrm{~mm}$ after treatment. For the postretention evaluation, in the long-term, $2.28 \mathrm{~mm}$ was found (Table 5). This shows a correction of $4.89 \mathrm{~mm}$, and an improvement in the post-retention period of $0.04 \mathrm{~mm}$ (Table 5). As shown in Table 6, after performing the ANOVA and Tukey tests, a statistically significant correction with treatment and a complete stability in the post-retention period could be noted, since there was no statistically significant difference of the canine relationship between the final and post-retention stages, and even a small improvement could be seen.

Kim and Little ${ }^{23}$ found results similar to the present study. The initial Class II canine relationship had value of $5.3 \mathrm{~mm}$, and at the end it was corrected to $1.6 \mathrm{~mm}$ and remained stable, showing the same value of $1.6 \mathrm{~mm}$ in the post-retention stage.

\section{Correlations}

To verify the correlation between the severity of the Class II relationship with the post-retention relapse, and the relapse of Class II molar relationship with treatment time, retention time and time of postretention evaluation, the Pearson correlation test was used (Tables 7 and 8).

There was a correlation of the initial canine relationship with relapse (Table 7).

There was correlation of molar relationship relapse with the time of post-retention evaluation (Table 8). However, this correlation was negative, indicating that the longer the time of post-retention evaluation, the lower the relapse of molar relationship. This finding seems unreasonable; however, since patients were mostly young, at the end of orthodontic treatment, they still showed growth in the post-retention stage. As the growth tends to improve the relationship of skeletal bases,${ }^{18}$ it is natural that the if time has passed until the post-retention evaluation, the patient will have more growth, favoring the stability of the correction of the Class II molar relationship.

\section{Intergroups comparison}

To check the influence of the severity of the Class II molar relationship in the initial stability of the molar relationship, the sample was divided into two groups: Group 1 with initial half-cusp or $3 / 4-$ cusp Class II molar relationship, and Group 2, with ini- 
tial complete Class II molar relationship. Therefore the independent $t$ test was applied for all variables between these two groups.

There was compatibility between the two groups for the initial and final ages, and only the post-retention age showed a statistically significant difference (Table 9). Subjects in Group 2 (complete Class II) had an older age in the post-retention stage than the subjects in Group 1. However, despite the complete Class II group had presented an older age in the postretention stage, the time of post-retention evaluation of this group was not statistically significant higher than the group with $1 / 2$-cusp and $3 / 4$-cusp Class II. The retention time was also compatible between the two groups studied (Table 9).

Regarding treatment time, the group with complete Class II showed longer treatment than the $1 / 2$-cusp and $3 / 4$-cusp Class II group, and this difference was statistically significant (Table 9). This was expected since it is known that the severity of malocclusion, especially the severity of the Class II, when treated without extractions, can significantly increase treatment time. , $^{6,20,40}$

Regarding the initial molar relationship, as group selection was based on the severity of this relationship, a significant difference between the groups, was expected (Table 9). Obviously, the complete Class II group had a significantly higher value than the group with less severity. The molar relationship at the end of treatment and at the post-retention stage did not differ between the two groups (Table 9). There was also a difference in the amount of correction with treatment, which also was expected, because if the Class II molar relationship was more severe in Group 2, a greater correction of this relationship was really necessary in this group (Table 9). The molar relationship relapse between the two groups did not present a statistically significant difference, however, it was observed that the molar relationship presented a relapse of $0.23 \mathrm{~mm}$ in the group with less severity and only $0.04 \mathrm{~mm}$ in the group with greater severity. This evidence reinforces the findings of this study that there is no relationship of the initial Class II severity with molar relationship relapse.

The same pattern of results was observed for the first and second premolars and canine relationship. There were statistically significant differences be- tween the two groups for these relationships in the initial $\left(\mathrm{T}_{1}\right)$ and final stage $\left(\mathrm{T}_{2}\right)$ and the change with treatment $\left(\mathrm{T}_{2}-\mathrm{T}_{1}\right)$ (Table 9$)$. For the relationships at the beginning of treatment, as explained above for the molar relationship, this result was expected due to the greater Class II severity in Group 2. Thus, it was also expected that the correction with treatment was greater, as confirmed by the results. However, there was also a significant result for these relationships at the end of treatment. Group 2, with complete Class II, presented a deficient finishing for the premolars and canine relationships.

A very important factor to be considered is the need for patient cooperation. The successful Class II malocclusion treatment without extractions is extremely connected to patient cooperation. It should be noted that a severe initial malocclusion, demands greater need for patient cooperation to achieve a satisfactory final result. ${ }^{6,42}$ According to Barros, ${ }^{6}$ the treatment of a complete Class II without extraction, in relation to two maxillary premolar extractions, requires approximately twice the degree of patient compliance.

Due to the fact that Group 2 includes only complete Class II malocclusion cases, it could be assumed that the greater severity of molar relationship at the beginning of treatment and hence the greatest amount of correction during treatment would influence the maintenance of long-term results. ${ }^{28} \mathrm{How}-$ ever, this association was not confirmed by the present study, since both groups had a stability without statistically significant differences for the molar, premolar and canine relationships.

Araki ${ }^{5}$ also found no major posttreatment changes in the group where the change of molar relationship was higher during treatment, and speculated that it probably occurred due to the proper retention of the dental relations obtained.

By studying the stability in the long-term posttreatment of Class II malocclusion by means of the Herbst appliance, Hansen, Pancherz and Hägg ${ }^{16}$ observed that, when the maxilla and the mandible are well connected in a stable Class I relationship, the strength of the maxillary growth can be transmitted to the mandible and vice versa. For this reason, it is essential to finish treatment with the best possible intercuspation. 


\section{FINAL CONSIDERATIONS}

It is considered that the stability of the correction of dental relationships, such as molar and canine relationships, are primary goals of a successful orthodontic treatment.

The stability of dental relationships is the most important aim to be achieved, ${ }^{36}$ because relapse was clearly considered, in a clinical assessment of dentists and patients, as the cause of dissatisfaction in relation to orthodontic treatment. The posttreatment changes of the skeletal characteristics have secondary importance, since they are not visible in the clinical evaluation, but should also be aimed, because these changes may reflect changes in tooth position. ${ }^{5}$

The present study demonstrated a relative occlusal stability of the molar, second and first premolars and canine relationships, as the posttreatment changes were minimal. This is a very important data for planning and treating the cases, because, apart from the cephalometric data of the patients, it is known that at least the occlusal relationship, considered as the most important, is almost maintained in the long-term.

It is also important to highlight that there is a wide individual variability of stability and relapse, since it has a multifactorial cause, and there are several factors related to it, such as craniofacial growth, patient compliance with the use of retainers. ${ }^{26}$

\section{CONCLUSIONS}

According to the studied sample and to the methodology used, it can be concluded that:

"There was a non significant relapse of molar relationship, on average $0.12 \mathrm{~mm}$. The relapses of premolars and canine relationships were also not significant.

"There was a significant correlation only between molar relationship relapse and time of post-retention evaluation.

"When the sample was divided into two groups, with half-cusp and 3/4-cusp Class II and with complete Class II at the beginning of treatment, no difference in the relapses of molar, premolars and canine relationships could be found .

" The Class II molar relationship correction remained stable and the initial severity did not influence molar relationship relapse. 


\section{REFERENCES}

1. Ackerman JL, Proffit WR. Soft tissue limitations in orthodontics: treatment planning guidelines. Angle Orthod. 1997:67(5):327-36.

2. Al Yami EA, Kuijpers-Jagtman AM, Vant Hof MA. Assessment of biological changes in a nonorthodontic sample using the PAR index. Am J Orthod Dentofacial Orthop. 1998:114(2):224-8.

3. Al Yami EA, Kuijpers-Jagtman AM, Vant Hof MA. Stability of orthodontic treatment outcome: follow-up until 10 years postretention. Am J Orthod Dentofacial Orthop. 1999:115(3):300-4.

4. Andrews LF. The six keys to normal occlusion. Am J Orthod 1972;62(3):296-309.

5. Araki JDV. Comparação cefalométrica da estabilidade do tratamento da má oclusão de Classe $\|$ realizado sem e com a extração de dois pré-molares superiores [dissertação]. Bauru (SP): Universidade de São Paulo; 2007.

6. Barros SEC. Avaliação do grau de eficiência do tratamento da Classe ॥ realizado sem extrações e com extrações de dois pré-molares superiores [dissertação] Bauru (SP): Universidade de São Paulo; 2004

7. Birkeland K, Furevik J, Bøe OE, Wisth PJ. Evaluation of treatment and posttreatment changes by the PAR Index. Eur J Orthod. 1997:19(3):279-88

8. Bishara SE, Hoppens BJ, Jakobsen JR, Kohout FJ. Changes in the molar relationship between the deciduous and permanent dentitions: a longitudinal study. Am J Orthod Dentofacial Orthop. 1988:93(1):19-28.

9. Brambilla AC. Comparação dos resultados oclusais do tratamento de Classe $\|$ realizado com extrações de dois pré-molares, com a terapêutica utilizando as extrações de quatro pré-molares [dissertação]. Bauru (SP): Universidade de São Paulo: 2002

10. Canut JA, Arias S. A long-term evaluation of treated Class II division 2 malocclusions: a retrospective study model analysis. Eur J Orthod. 1999:21(4):377-86.

11. Dahlberg G. Statistical methods for medical and biological students. New York: Interscience; 1940
12. Fidler BC, Artun J, Joondeph DR, Little RM. Long-term stability of Angle Class II, division 1 malocclusions with successful occlusal results at end of active treatment. Am J Orthod Dentofacial Orthop. 1995;107(3):276-85

13. Freitas KM, Janson G, Freitas MR, Pinzan A, Henriques JF, Pinzan-Vercelino $\mathrm{CR}$. Influence of the quality of the finished occlusion on postretention occlusal relapse. Am J Orthod Dentofacial Orthop. 2007:132(4):428.e9-14.

14. Graber TM, Vanarsdall RLJ. Orthodontics: current principles and techniques. St. Louis: Mosby; 1994.

15. Han UK, Vig KW, Weintraub JA, Vig PS, Kowalski CJ. Consistency of orthodontic treatment decisions relative to diagnostic records. Am J Orthod Dentofacial Orthop. 1991;100(3):212-9.

16. Hansen $\mathrm{K}$, Pancherz $\mathrm{H}$, Hagg U. Long-term effects of the Herbst appliance in relation to the treatment growth period: a cephalometric study. Eur J Orthod. 1991;13(6):471-81.

17. Harris EF, Behrents RG. The intrinsic stability of Class I molar relationship: a longitudinal study of untreated cases. Am J Orthod Dentofacial Orthop 1988:94(1):63-7.

18. Harris EF, Vaden JL, Dunn KL, Behrents RG. Effects of patient age on postorthodontic stability in Class II, division 1 malocclusions. Am J Orthod Dentofacial Orthop. 1994;105(1):25-34.

19. Houston WJB. The analysis of errors in orthodontic measurements. Am J Orthod. 1983:83(5):382-90.

20. Janson G, Barros SE, Freitas MR, Henriques JF, Pinzan A. Class II treatment efficiency in maxillary premolar extraction and nonextraction protocols. Am J Orthod Dentofacial Orthop. 2007:132(4):490-8.

21. Karlsen AT. Craniofacial characteristics in children with Angle Class II div. 2 malocclusion combined with extreme deep bite. Angle Orthod. 1994:64(2):123-30

22. Kim JC, Mascarenhas AK, Joo BH, Vig KW, Beck FM, Vig PS Cephalometric variables as predictors of Class II treatment outcome. Am J Orthod Dentofacial Orthop. 2000;118(6):636-40 
23. Kim TW, Little RM. Postretention assessment of deep overbite correction in Class II Division 2 malocclusion. Angle Orthod. 1999;69(2):175-86.

24. Litowitz R. A study of the movements of certain teeth during and following orthodontic treatment. Angle Orthod. 1948;18(3):113-31.

25. Little RM. Stability and relapse of mandibular anterior alignment University of Washington studies. Semin Orthod. 1999:5(3):191-204.

26. Little RM, Wallen TR, Riedel RA. Stability and relapse of mandibular anterior alignment - first premolar extraction cases treated by traditional edgewise orthodontics. Am J Orthod. 1981;80(4):349-65.

27. Mavropoulos A, Karamouzos A, Kiliaridis S, Papadopoulos MA. Efficiency of noncompliance simultaneous first and second upper molar distalization: a three-dimensional tooth movement analysis. Angle Orthod. 2005:75(4):532-9.

28. Nashed RR, Reynolds IR. A cephalometric investigation of overjet changes in fifty severe Class II division I malocclusions. Br J Orthod. 1989;16(1):31-7.

29. Nett BC, Huang GJ. Long-term posttreatment changes measured by the American Board of Orthodontics objective grading system. Am J Orthod Dentofacial Orthop. 2005;127(4):444-50

30. Ngantung V, Nanda RS, Bowman SJ. Posttreatment evaluation of the distal jet appliance. Am J Orthod Dentofacial Orthop. 2001;120(2):178-85

31. O'Brien KD, Robbins R, Vig KW, Vig PS, Shnorhokian H, Weyant R. The effectiveness of Class II, division 1 treatment. Am J Orthod Dentofacial Orthop. 1995:107(3):329-34

32. Omblus J, Malmgren $O$, Pancherz H, Hägg U, Hansen K. Long-term effects of Class II correction in Herbst and Bass therapy. Eur J Orthod. 1997:19(2):185-93

33. Ormiston JP, Huang GJ, Little RM, Decker JD, Seuk GD. Retrospective analysis of long-term stable and unstable orthodontic treatment outcomes. Am J Orthod Dentofacial Orthop. 2005;128(5):568-74.
34. Pancherz H, Ruf S, Kohlhas P. Effective condylar growth and chin position changes in Herbst treatment: a cephalometric roentgenographic longterm study. Am J Orthod Dentofacial Orthop. 1998;114(4):437-46.

35. Pancherz H, Zieber K, Hoyer B. Cephalometric characteristics of Class II division 1 and Class II division 2 malocclusions: a comparative study in children. Angle Orthod. 1997;67(2):111-20

36. Sadowsky C, Sakols EI. Long-term assessment of orthodontic relapse. Am J Orthod. 1982:82(6):456-63.

37. Salzmann JA. Practice of Orthodontics. Philadelphia: J. B. Lippincott Company; 1966

38. Thilander B. Orthodontic relapse versus natural development. Am J Orthod Dentofacial Orthop. 2000:117(5):562-3.

39. Uhde MD, Sadowsky C, Begole EA. Long-term stability of dental relationships after orthodontic treatment. Angle Orthod. 1983:53(3):240-52

40. Valarelli FP. Relação entre o grau de severidade e o sucesso do tratamento sem extração da má oclusão de Classe II [tese]. Bauru (SP): Universidade de São Paulo; 2006.

41. Vig KW, Weyant R, Vayda D, O'Brien K, Bennett E. Orthodontic process and outcome: efficacy studies - strategies for developing process and outcome measures: a new era in orthodontics. Clin Orthod Res. 1998:1(2):147-55

42. Wheeler TT, McGorray SP, Dolce C, Taylor MG, King GJ. Effectiveness of early treatment of Class II malocclusion. Am J Orthod Dentofacial Orthop. 2002;121(1):9-17.

43. Woods M, Lee D, Crawford E. Finishing occlusion, degree of stability and the PAR index. Aust Orthod J. 2000;16(1):9-15 